\title{
Research on Marketing Strategy of H1D
}

\author{
Yali Luo \\ School of Management, Wuhan University of Technology, Wuhan, China \\ 1142669403@qq.com
}

\begin{abstract}
Keywords: H1D; Dairy; Fresh house package; Marketing strategy; Social responsibility
\end{abstract}
\begin{abstract}
In recent years, living standards has gradually improved, the demand of dairy products has continually increased, and then dairy market competition is fiercer than ever. How to optimize the product structure, how to broaden and deepen business sales channels and how to increase the propaganda has become a problem managers concerned. In addition, Guizhou dairy processing industry started relatively late, the management system is not perfect, which leads to the dairy manufacturing enterprises lose their own core competitiveness, fail to occupy a lot of market share and create greater customer value. By taking H1D as a subject, according to marketing theory, and looking through relevant literature, this paper will work on H1D's marketing strategy, discover the problems of the marketing aspects of this company and then further optimize the company's marketing strategy and promote the popularity of the company brand. It is prospected that this research would prompt H1D to find problems in the marketing links, take timely measures, actively optimize the product structure, expand sales channels, increase publicity efforts, improve the comprehensive core competitiveness of enterprises, promote the popularity of brand and create greater value for customers.
\end{abstract}

\section{Introduction}

Marketing theory originated in the United States in the 1920s, the emergence and development of marketing theory has gone through five periods: the budding period, the functional research period, the formation and consolidation period, the marketing management orientation period and the coordination and development period [1]. Chinese marketing theory began in the late 1970s, on the basis of studying and learning from the research results of Western scholars, and then combining the foreign marketing theory with Chinese national conditions and the characteristics of Chinese enterprises, which is benefit for the research and exploration on marketing theory of Chinese enterprises.

The marketing strategy which fits the development of company not only helps to increase the turnover of the company and improve customer loyalty, but also helps to promote the realization of enterprise strategy. Many firms are beginning to realize that they are members of the wider community and therefore must behave in an environmentally responsible fashion. Firms marketing goods with environmental characteristics will have a competitive advantage over firms marketing non-environmentally responsible alternatives. Many firms are striving to become more environmentally responsible, in an attempt to better satisfy their consumer needs.

The purpose of this paper is to systematically analyze the current marketing situation of the case company in the product portfolio width, sales channel and brand awareness and other aspects, and then find the marketing problems of this company in the daily operation. After that, analysis these marketing issues one by one and provide effective marketing strategies with their own characteristics.

This paper mainly draws on system method, analysis induction method and literature research method, and discusses the current situation of HID product structure, channel deepening and promotion means systematically. What's more, it analyzes the shortcomings and puts forward some suggestions on how to solve the problem of HID's product structure, channel deepening and promotion means. 


\section{The Current Marketing Situation of H1D}

Present Products. H1D's main business products are shown in Table 1.

Table 1 H1D's Main Business Products

\begin{tabular}{|c|c|c|}
\hline Product Series & Product Category & Product Name \\
\hline \multirow{2}{*}{ Fresh Roof Package Series } & Fresh Milk & H1D Natural Pure Milk \\
\cline { 2 - 3 } & \multirow{2}{*}{ Yogurt } & H1D Matcha Yogurt \\
\cline { 2 - 3 } & & H1D Aloe Vera Fruit Yogurt \\
\cline { 2 - 3 } & & H1D Pineapple Pie Yogurt \\
\hline Fresh Tube Series & Breakfast Milk & H1D Fresh Breakfast Breakfast Milk \\
\hline Table Series & Table Milk & H1D Table Milk \\
\hline Ice Cream Series & Cold Goods & Fresh Ice Cream \\
\hline
\end{tabular}

Present Channels. In the direct sales model, H1D build their own stores generally opened in community, schools, institutions, canteens, breakfast shops and convenience stores and so on. However, there are some risk and barriers to entry in this special channel [2]. On the other hand, H1D combines primary channel with level-two channel in the indirect channel model. In the first channel, H1D's products will enter the supermarkets and canteens where other enterprises will also enter, and then, in the next channel, H1D draws on the franchisee model.

Present Promotions. H1D not only continuously optimize their management and production system to ensure development, but also vigorously join the public and return to society. According to the public relations in the promotion theory, the company makes good use of media to achieve the effect of information transmission and improve its image, which is benefit for more and more customers recognize their culture concept, and thus promote product sales.

Other States. H1D draws on fresh house box process, which is biodegradable, no plasticizer, effective light avoidance. In addition, this process is very convenient, without straw can taste the long-awaited fresh milk. Fig. 1 shows this environmentally friendly and fashion way to open the box.
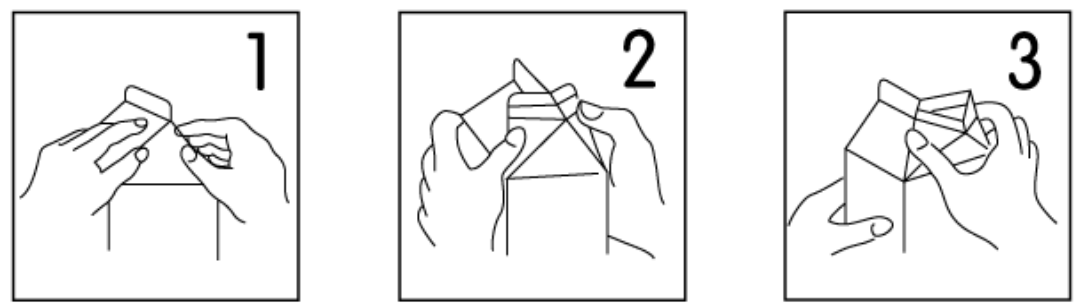

Figure 1. the Method of Opening the Fresh Box

There are three steps: the first step is to open two sides to the exit; the second step is to push the left and right sides to the end; the last step is to squeeze into the export.

\section{Analysis of H1D Marketing Problem}

Product Structure Is Single. Fresh tube series aim at the supply of breakfast milk, and the taste is single, which does not meet the breakfast milk taste needs of majority consumers.

The table series only provide one kind of milk, which cannot meet the needs of customers. Moreover, the current awareness of consumer about it is not enough, so H1D should increase publicity, so that more customers can understand the difference of table milk.

As for the ice cream series, the market input of these products is less. It is difficult to meet the needs of customers.

Channel Coverage Is Narrow. Channel model is divided into two types: direct and indirect channels. Direct channels do not include brokers. Indirect channel is divided into one-level channel, two-level channels, and three-level channels by the middle of the number of layers. 1) The number 
of stores in the company is small. The company only set up their own stores in the community, schools, institutions, canteens, breakfast shops and convenience stores [3]. Although the amount of customers is stable, the purchasing power of these channels is limited, which cannot create more customer value. 2) The number of brokers is small and the localized market is serious. Although agents are invited to join in the company, the number of brokers is still not big. And in other cities in Guizhou, it is difficult to purchase H1D's products. Therefore, H1D should build other markets in Guizhou as soon as possible. 3) There is no online sales channel in H1D. Considering the characteristics of products, there is no products of H1D in major business platform such as Jingdong and TaoBao. However, with the development of B2C mode, H1D should try to combine online trading with offline experience, which is good for broadening the network of channel.

Propaganda Should Be Strengthened. 1) The information on the official website is not perfect. H1D's official website information is not perfect, for example, there is no detailed description of their products, which leads many people who want to understand H1D especially brokers cannot quickly and efficiently find related information and business policies [4]. In addition, the recruitment information is very simple, for example, there is no detailed description of the post demand of the company. That is to say, job-hunter loses a chance to find a suitable job, at the same time, H1D face the loss of excellent people. 2) The official microblogging of the enterprise is useless [5]. Although H1D has been registered in Sina microblogging, the microblogging only obtain 101 fans and does not publish any blog posts, which is not conducive to increase promotion and the spread of corporate brand value. This leads to asymmetric information between H1D and customers, which does not achieve effective two-way communication. Therefore, H1D loses a great deal of potential customers. 3) Advertising investment is less. First of all, making less use of television advertising especially in the local television media, which leads to cannot bring visual and auditory experience to customers and enhance the brand awareness of H1D. Secondly, although the local press media have reported the information of the case company, this is only in recent years. In addition, the newspaper coverage is narrow, for those customers who do not often read newspaper, they cannot understand the company's brand and product clearly [6]. Last but not least, there is no Internet advertising investment. More and more people contact the network, and online advertising has been accepted by them. Therefore, many businesses have also joined in network advertising, in order to let their products know. However, H1D needs to increase online advertising investment. Advertising is a good way to persuade customers to buy. Advertising can achieve the following possible goals: firstly, company can communicate with customers about the value of their product with informative advertising, indicate the new use of the product and establish corporate brand and image. Meanwhile, company also can confer the information of price and the release of new products, and describe the available services and support; secondly, the company can also build brand preferences through persuasive advertising, cultivate customer loyalty, change the customer's understanding of the value of the product, and then persuade consumers to recommend the brand to others; thirdly, it is good for reminding the manufacturer to help manufacturers to maintain customer relationships.

\section{Marketing Strategy of H1D}

Optimizing the Product Structure to Meet Market Demand. Product line, also known as product category, refers to a series of products which have the similar and closely related functions. These products are often bought by the same customer groups. Because of the similar channels for distribution, the price of them is basically the same. When develop product line, company can consider as follows: deleting the existing product lines, reducing unnecessary ones, and adding imperfect ones. Product line added refers to the addition of new projects; product line deletion refers to the deletion of the object of the recession; product line characteristics refers to one or several finished products with company characteristics; product line extension has three options: down extension, upward extension and bidirectional extension.

The four dimensions of the product portfolio are as follow: width refers to the number of product lines; length refers to the total number of products; depth refers to the number of individual product 
specifications, forms or colors; relevance refers to the product line between the correlation or close degree. 1) Optimization Strategy of Product Line. To continue the strategy of the new roof package product line, but should combine it with the product line extension strategy [7]. In this way, customers can buy high quality and inexpensive products. 2) Optimization Strategy of Product Portfolio. First of all, in order to increase the repeat purchase rate of customers and create a good reputation of the marketing environment, the company should broaden the width of the product portfolio. After optimizing the internal process and resources, H1D can enter the research and production of fresh milk products at room temperature. Secondly, with the arrival of the twins and the birth of the peak of 90, the maternal and child markets has become the sunrise industry where a lot of business want to enter. However, H1D is still only engaged in the production and sale of simple pasteurized milk. In order to get more market share and enhance brand awareness, H1D have to enter the milk powder industry. Last but not least, nowadays, yogurt and its beverage series is very popular. In order to increase the company's market share, H1D can produce yogurt and its beverage products after doing a lot of market researches. And then, H1D can design new and special products for customers in order to obtain more and more market shake.

Broadening the Channel to Achieve the Purchase Convenience. Channel likes water. The sales channel of the company meaning has become more and more significant. With the development of Internet, there is a great deal of knowledge and information. Diversified development pattern has become a new tendency. The traditional and single channel model cannot work. Increasingly competitive environment forces enterprises to innovate and combine online with offline. 1) Settling in large supermarkets and roadside convenience stores. At present, H1D does not have a strategic partnership with large supermarkets in urban and rural areas, which leads to many existing customers especially those living near these large supermarkets find it very difficult to buy H1D's product. In addition, even in the convenience store at the roadside, it is also very diff icult to see H1D products, which is not conducive to establish a good customer relationship. Once the customers lose, it is hard for the company to recover again. In short, H1D should cooperate with large supermarkets, roadside convenience stores, canteen and other retailers. 2) Finding new franchisees in the undeveloped area. Although H1D has established its own distribution channels, there are still many blank areas in the distribution network [8]. For example, it is difficult to see H1D's product except Guiyang. Therefore, the company should do a good job in planning and find other regions' franchisees. 3) Putting products in the major business platform. With the development of B2C model, the shopping habits and experience of modern people has undergone tremendous changes. With the development of mobile phones and computers, consumers are more willing to choose online shopping to pick their favorite products. This is a universal online shopping era, more and more businesses choose to cooperate with the major business platform to broaden the enterprise sales channels. Channel stimulation is the corporate behavior that manufacturer draws on continuous stimulation initiatives to stimulate the intermediate channel members, and then stimulate the salesperson's enthusiasm for distribution and improve the efficiency of distribution. Channel managers strengthen the needs of channel members through a series of material or spiritual stimulation to enhance the competition among members of the channel. What's more, in this way, company also can enhance channel members' work enthusiasm and operational efficiency, and then achieve business goals. After choosing the proper channel members, channel managers should strive to cultivate and promote a good partnership between members to enhance the overall operating efficiency of the channel, which is inseparable from the daily work of the supervision and incentives. At the same time, the daily supervision and encouragement of the middlemen is also one of the effective ways to eliminate conflict and contradiction in the channel in time.

Increasing the Way of Promotion and Cultivating Brand Awareness. China introduced the concept of microblogging in 2002, and then caused a huge response in the country. At the same time, it increases at high speed, so microblogging has become the powerful tools that more and more enterprises to publish information. 1) Updating the official website of the enterprise information timely [9]. The perfect information description of products helps consumers understand the performance of products, increase the understanding of business ideas, stimulate customers' 
immediate or repeating purchase and build a good customer relationship. Complete recruitment information is benefit for you to accurately locate the company's current vacancies to facilitate the needs of candidates quickly. Complete investment information makes brokers clear about H1D. 2) Increasing the amount of corporate official microblogging [10]. Today, the use of microblogging is growing, not less than QQ, WeChat and other social software. So the speed of information dissemination cannot be overlooked. Unfortunately, H1D's microblogging marketing capacity is limited. 3)Increasing advertising investment. First of all, sophisticating advertising in the local television station and broadcast so that more consumers can understand the H1D's product information. And the advertising have to highlight the difference between H1D and other dairy enterprises so that reduce the customers' concerns. Secondly, our daily life is closely related with the Internet, increasing the Internet advertising investment can increase the company's influence in the Internet and obtain the Internet customers' attention. Thirdly, to create exquisite outdoor advertising. Outdoor advertising can bring more consumers, increase profitability and create greater profit margins.

\section{Conclusion}

With the accelerated pace of building a well-off society, the diet structure of residents has changed. The concept of high quality of life enjoys popular support, the demand of nutrients gradually is increasing. Dairy processing industry has become the sunrise industry.

In this paper, the following conclusions are obtained: 1)The current marketing situation of H1D. This paper has a detailed description of product structure, channel coverage, publicity and corporate characteristics. With the development of society, the feedback of community from companies is conducive to enhance the company's image. 2)The marketing issues of H1D. This paper systematically analysis the marketing problems of H1D, namely: single product structure, narrow channel coverage and single publicity. The existence of these problems is not conducive to the transmission of corporate culture, cultivate brand awareness, obtain market share and create profits for customers. 3)The marketing strategies of H1D. This paper proposes strategies from product structure, channel deepening and diversification of promotions.

In addition, due to the limited ability of the author, the research on this industry is not deep enough, which affects the optimization of H1D marketing strategy. What's more, the other companies in the industry and other related areas involved less, there are imperfections.

\section{References}

[1] J. Empen, J. Loy, and C. Weiss: European Journal of Marketing, Vol. 49 (2015) No.5-6, p.736.

[2] F. Yao: Marketing Frontier and Skill Training, Dalian University of Technology Press, China, 2013, p.123. (In Chinese)

[3] L. Shnayder, F.J. Rijnsoever and M.P. Hekkert: Journal of Cleaner Production, Vol.122 (2016) p.212.

[4] R.H. Zheng: Channel Management, Dalian University of Technology Press, China, 2013, p.146. (In Chinese)

[5] Q.S. Lu, Y. Yang and U. Yuksel, Annals of Tourism Research, Vol.54 (2015) p. 136.

[6] Y.J. Feng: Network Marketing Foundation and Practice, Tsinghua University Press, China, 2013, p.240. (In Chinese)

[7] G. Wagner, H. Schramm and S. Steinmann: Journal of Retailing and Consumer Services, Vol.34 (2017) p.278.

[8] C. Zhang: Marketing channel management, Tsinghua University Press, China, 2014, p.167. (In Chinese) 
[9] H.M. Wang, P.H. Chen, H.K. Yu and C.Y. Hsiao: Journal of Business Research, Vol.68 (2015) No.11, p.2232.

[10]X.G. Kang: Marketing, Shanghai Academy of Social Sciences, China, 2015, p.110. (In Chinese) 